\title{
Identification of epithelialization in high transsphincteric fistulas
}

\author{
L. E. Mitalas • R. S. van Onkelen • K. Monkhorst • \\ D. D. Zimmerman • M. P. Gosselink • \\ W. R. Schouten
}

Received: 12 September 2011 / Accepted: 10 December 2011/Published online: 10 January 2012

(C) The Author(s) 2012. This article is published with open access at Springerlink.com

\begin{abstract}
Background At present, transanal advancement flap repair (TAFR) is the treatment of choice for transsphincteric fistulas passing through the upper and middle third of the external anal sphincter. It has been suggested that epithelialization of the fistula tract contributes to the failure of the treatment. The aim of this study was to assess the prevalence of epithelialization of the fistula tract and to study its effect on the outcome of TAFR and TAFR combined with ligation of the intersphincteric fistula tract (LIFT).

Methods Forty-four patients with a high transsphincteric fistula of cryptoglandular origin underwent TAFR. Nine of these patients underwent a combined procedure of TAFR with LIFT. In all patients the fistula tract was excised from the external opening up to the outer border of the external anal sphincter. In patients undergoing TAFR combined with LIFT an additional central part of the intersphincteric fistula tract was excised. A total of 53 specimens were submitted. Histopathological examination of the specimens was carried out by a pathologist, blinded for clinical data. Results Epithelialization of the distal and intersphincteric fistula tract was observed in only 25 and $22 \%$ of fistulas, respectively. There was no difference in outcome between fistulas with or without epithelialization.
\end{abstract}

L. E. Mitalas · R. S. van Onkelen - D. D. Zimmerman ·

M. P. Gosselink · W. R. Schouten ( $\square)$

Division of Colon and Rectal Surgery, Department of Surgery,

Erasmus MC, University Medical Center,

H 181,'s Gravendijkwal 230, 3015 CE Rotterdam,

The Netherlands

e-mail: w.r.schouten@erasmusmc.nl

K. Monkhorst

Department of Pathology, Erasmus MC, University Medical

Center, Rotterdam, The Netherlands
Conclusions Epithelialization of high transsphincteric fistulas is rare and does not affect the outcome of TAFR and TAFR combined with LIFT.

Keywords Transanal advancement flap repair . Ligation of the intersphincteric fistula tract . Transsphincteric fistulas · Epithelialization

\section{Introduction}

The main objective in the treatment for fistulas, passing though the upper or middle third of the external anal sphincter, is healing of the fistula without subsequent damage to both sphincters. Although transanal advancement flap repair (TAFR) provides a useful tool for achieving this goal, fistula healing fails in one out of every three patients [1-8]. Several studies have been conducted to identify factors affecting the outcome of TAFR. However, until now, no definite factor predisposing to failure has been determined.

In 1995, Lunniss et al. [9] observed epithelium lining the intersphincteric fistula tract in 13 out of 18 patients with a low perianal fistula. Though the effect of this epithelialization on fistula healing was not assessed, the authors stated that this might be a cause for the persistence of the fistula. This hypothesis is still generally accepted, and this study is cited in many papers and text books [10-13].

Recently Van Koperen et al. [14] also assessed the presence of epithelium in fistula tracts. In 18 patients with a low transsphincteric fistula they took biopsies at three different locations, on the side of the internal opening, in the middle of the fistula tract, and near the distal end close to the external opening. Epithelium was predominantly found near the internal opening. In the other parts of the 
fistula tract, epithelialization was found to be rare. According to these authors epithelialization might contribute to the failure of healing, although they did not provide evidence for this statement.

The aim of the present study was to assess the prevalence of epithelialization of the fistula tract and to study the effect of epithelialization on the healing rate.

\section{Materials and methods}

Between June 2008 and December 2009, 44 consecutive patients were enrolled in this study. The series comprised 30 men and 14 women. Median age at the time of repair was 46 years (range, 21-67 years). Median time interval since the onset of the fistula was 17 months (range, 5-73 months). Two patients underwent preoperative seton drainage for at least 2 months, until the day of the flap repair. Forty patients underwent a primary intervention, and 4 patients underwent secondary intervention after previous TAFR. In all patients the fistula tract crossed the upper or middle third of the external anal sphincter. All operations were performed by one surgeon (W.R.S.). Between June 2008 and January 2009, 35 patients underwent TAFR. In February 2009 ligation of the intersphincteric fistula tract (LIFT) was added to flap repair. In all patients the fistula tract was excised from the external opening up to the outer border of the external anal sphincter. In the nine patients who underwent a combined procedure, the central part of the intersphincteric fistula tract was also harvested. A total of 53 specimens were submitted for histopathological examination.

\section{Exclusion criteria}

Patients with a rectovaginal fistula or a fistula due to Crohn's disease were excluded from the present series.

\section{Preoperative}

Patients underwent complete mechanical bowel preparation (polyethylene glycol: Klean-prep ${ }^{\circledR}$ Helsinn Birex Pharmaceuticals, Dublin, Ireland). After induction of general endotracheal anesthesia, metronidazole (500 mg) together with cefuroxime $(1,500 \mathrm{mg})$ was administered intravenously.

\section{Operative technique TAFR}

After the patient was placed in the prone jackknife position, the external opening was enlarged. The fistula tract was excised as far as possible, up to the outer border of the external anal sphincter and submitted for histopathological examination. The internal opening of the fistula was exposed using a Lone Star retractor (Lone Star Retractor System, Lone Star Medical Products ${ }^{\circledR}$, Inc. Houston, TX, USA). The crypt-bearing tissue around the internal opening as well as the overlying anodermis was then excised. The fistula tract was cored out of the sphincters. The defect in the internal anal sphincter was closed with absorbable sutures. A flap consisting of mucosa, submucosa and some of the most superficial fibers of the internal anal sphincter was raised from the level of the dentate line and mobilized over a distance of 4 to $6 \mathrm{~cm}$ proximally. The flap was advanced and sutured to the neodentate line with absorbable sutures.

\section{Operative technique LIFT}

With the patient in the prone jackknife position, a probe was introduced into the fistula tract. A curvilinear incision was made in the intersphincteric groove, and the fistula tract was identified with the probe in situ. Care was taken not to injure the anal sphincters. After the dissection of the fistula tract, the probe was removed. The intersphincteric fistula tract was ligated near the internal and external anal sphincters. The central part of the intersphincteric fistula tract was excised and submitted for histopathological examination. Finally, the wound in the intersphincteric groove was closed with non-absorbable sutures.

\section{Postoperative}

All patients were immobilized for 5 days. All patients received a clear liquid diet for 5 days. During this time period, metronidazole and cefuroxime were administered intravenously three times daily.

\section{Histopathological examination}

After fixation in $10 \%$ formalin, the 53 specimens were cut in sections. These sections were strained using the routine hematoxylin and eosin staining method. Pan keratin antibodies were used for the detection of keratins, which are intermediate filament proteins expressed mainly in epithelial cells. The histopathological examination of the fistula tract was carried out by a pathologist, blinded for clinical data.

Statistical analysis

Comparison of the changes between groups was conducted using the Fisher's exact probability test. The limit of statistical significance was set at $P=0.05$. 


\section{Results}

Median follow-up was 11 months (range, 6-13 months). The healing rate after surgery was $68 \%$.

\section{Epithelialization}

In the fistula tracts extending from the external opening up to the outer border of the external anal sphincter, epithelialization was observed in 11 specimens $(25 \%)$. In 5 of these patients the fistula tracts were completely lined with epithelium (Fig. 1), while in 6 patients the specimens were only partly lined with epithelium (Fig. 2). In the other specimens (75\%) granulation tissue was observed (Fig. 3).

In the intersphincteric fistula tract epithelium lining was observed in 2 specimens (22\%). In both specimens the epithelial lining was complete. The fistula tract extending from the external opening up to the outer border of the

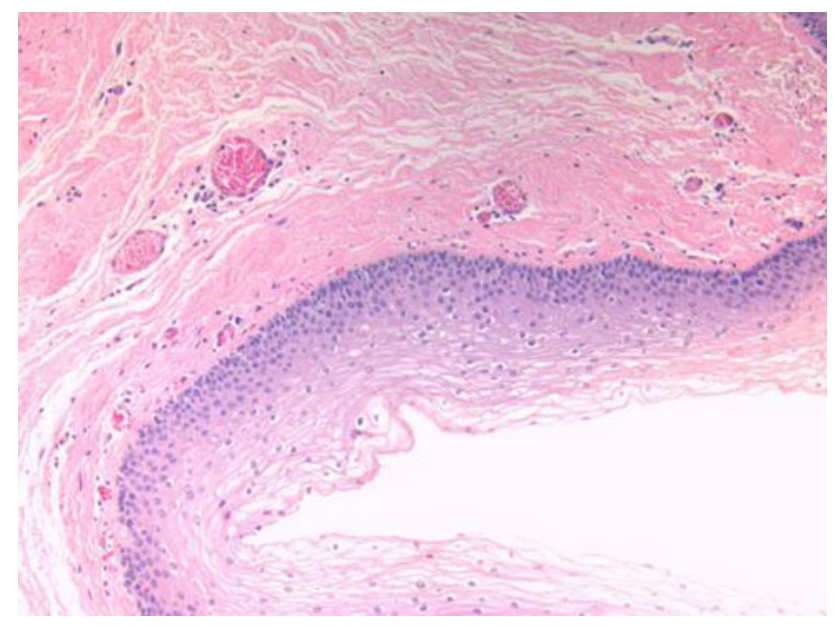

Fig. 1 Complete epithelial lining

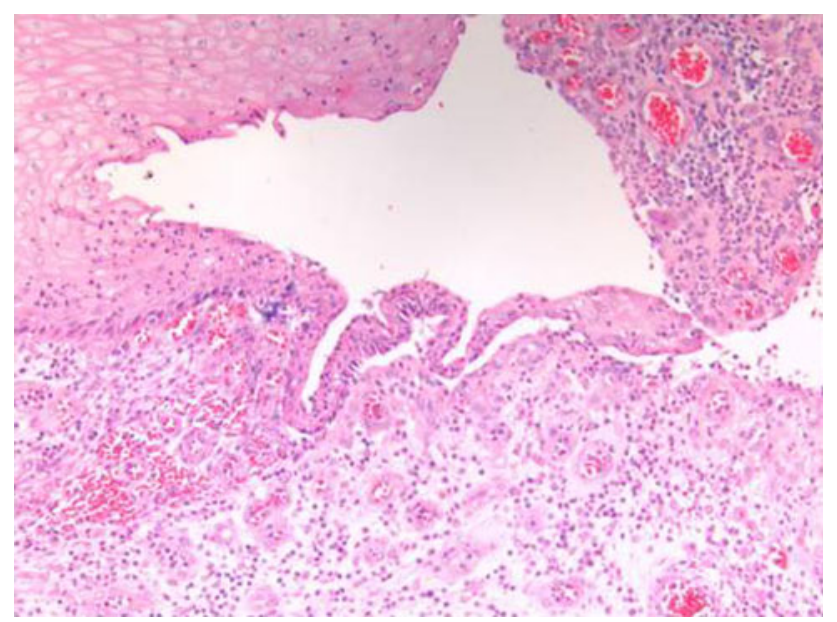

Fig. 2 Incomplete epithelial lining

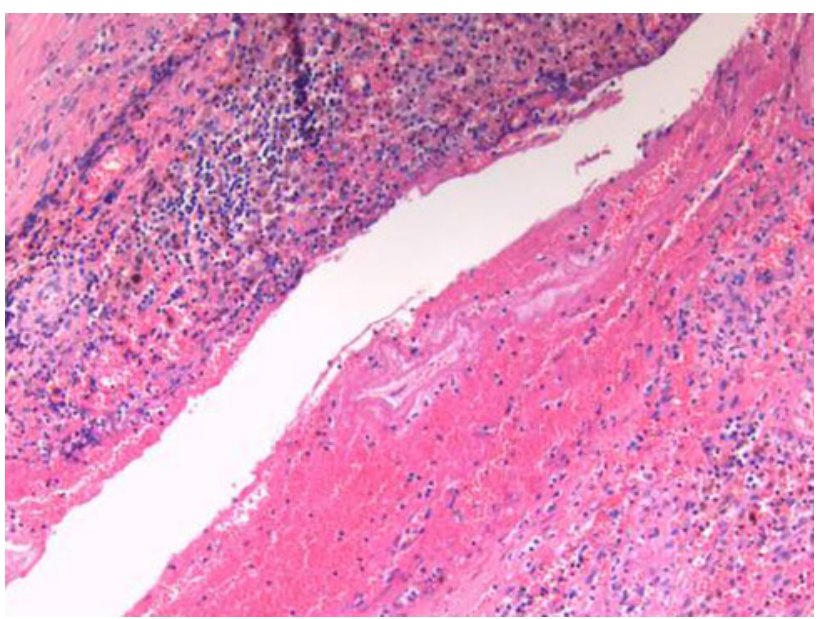

Fig. 3 Granulation tissue

Table 1 Overview of results based on presence or absence of epithelialization

\begin{tabular}{llll}
\hline & Epithelialization & No-epithelialization & $P$ value \\
\hline Number of patients & 11 & 33 & \\
Age (years) & 42 & 48 & 0.42 \\
Gender (\% male) & 64 & 70 & 0.68 \\
Time interval since & 19 & 16 & 0.43 \\
$\quad$ onset & & 70 & 0.55 \\
Healing rate $(\%)$ & 64 & & \\
\hline
\end{tabular}

external anal was also completely lined with epithelium in these 2 patients. In the other specimens $(78 \%)$ the fistula tract was lined with granulation tissue.

No anal gland tissue with mucin-producing cells could be detected in any of the patients.

\section{Outcome}

There was no difference in healing rate between fistulas with or without epithelialization, as shown in Table 1. We found no correlation between either the time interval since onset of the fistula or prior seton drainage, and the presence of epithelium.

\section{Discussion}

Transanal advancement flap repair provides a useful tool for the treatment of high transsphincteric fistulas. Recent studies indicate that this procedure fails in one of the every three patients. Potential risk factors for failure, such as gender, age, body mass index, prior attempts at repair, rectal mucosal blood flow and previous use of a seton, have been analyzed $[15,16]$. Until now, no definite risk factor 
for failure has been identified. In the present study, similar healing rates were observed in patients with and those without epithelialization of their fistula tract. This finding indicates that epithelialization does not affect the outcome of TAFR and TAFR combined with LIFT.

In 1995, Lunniss et al. [9] were the first to describe the epithelialization of perianal fistulas. They observed epithelium lining in 13 out of 18 patients. However, they did not mention whether the fistula tract was completely or partly lined with epithelium. Though the effect of epithelialization on fistula healing was not assessed, the authors stated that epithelialization might contribute to the persistence of fistulas. This hypothesis is still generally accepted, despite the lack of evidence [17, 18]. Recently, Van Koperen et al. [14] examined the presence of epithelium in fistula tracts. In 18 patients with a low transsphincteric fistula they took biopsies from the fistula tract from 3 different locations, at the side of the internal opening, in the middle of the fistula tract, and near the distal end close to the external opening. At the side of the internal opening, epithelialization was observed in the majority of patients. In our opinion this epithelium does not represent epithelialization of the fistula tract since it is most likely derived from the epithelium lining of the crypts of Morgagni and the anal glands.

Epithelialization was observed in 4 biopsies taken from the middle of the fistula tract and in only 2 biopsies taken from the distal end close to the external opening. These latter findings are almost similar to those obtained from the present study. Though epithelialization was observed almost exclusively near the internal opening and only a few fistula tracts were completely epithelialized, Van Koperen et al. stated that epithelialization of fistula tracts is present in most patients and might contribute to failure. In our opinion their study does not provide evidence for the adverse effect of epithelialization on fistula healing.

Kiehne et al. compared squamous epithelium, obtained from perianal fistulas, with perianal skin and rectal mucosa. They found that the epithelial lining of fistulas expresses identical cytokeratins and similar levels of antimicrobial peptides as perianal skin. Based on this finding, they suggested that epithelialization of perianal fistulas starts at the side of the external opening and serves as a defense mechanism to prevent local and systemic infection by microbes from fecal material passing through the fistula tract [19]. According to these authors, epithelium growth in perianal fistulas is a late event. However, they did not assess the time interval between the onset of fistula development and the beginning of epithelialization. In the present study the median time interval since the onset of fistula development did not differ between patients with and without epithelial lining of their fistula. It is not known why epithelialization does not occur in every fistula at the same stage. It has been suggested that perpetuation of inflammation prevents the migration and arrangement of myofibroblasts, which are the key cells in the events of tissue repair [20]. These cells are able to form a new basement membrane, which is a prerequisite for the migration of epithelial cells. In the present study epithelialization of the distal and intersphincteric fistula tracts was found in only 25 and $22 \%$ of fistulas, respectively. The lack of epithelialization in the majority of our patients may be an expression of ongoing inflammation. Based on this assumption, one would expect a worse outcome after flap repair in patients without epithelialization of their fistula. However, in the present study similar healing rates were found in patients with and those without epithelial lining. Based on this observation, it seems obvious that epithelialization, like many other factors, does not adversely affects the outcome of flap repair. In a previous study we assessed the outcome of repeat flap repair in patients, who encountered a failure after the initial procedure. In all patients we noticed complete healing of the flap, except at the site of the original internal opening [21]. This remarkable finding does suggest that ongoing inflammation in the remaining fistula tract contributes to persistence of the fistula. Further studies are warranted to examine the microbiologic and immunologic characteristics of this inflammatory process.

\section{Conclusions}

In contrast to what is generally accepted, most perianal fistulas are not lined with epithelium. Moreover, the presence of epithelium lining does not affect the outcome after TAFR.

Conflict of interest The authors declare that no conflict of interest exists.

Open Access This article is distributed under the terms of the Creative Commons Attribution Noncommercial License which permits any noncommercial use, distribution, and reproduction in any medium, provided the original author(s) and source are credited.

\section{References}

1. Miller GV, Finan PJ (1998) Flap advancement and core fistulectomy for complex rectal fistula. Br J Surg 85:108-110

2. Mitalas LE, Gosselink MP, Oom DM, Zimmerman DDE, Schouten WR (2009) Required length of follow-up after transanal advancement flap repair of high transsphincteric fistulas. Colorectal Dis 11:726-728

3. Schouten WR, Zimmerman DDE, Briel JW (1999) Transanal advancement flap repair of transsphincteric fistulas. Dis Colon Rectum 42:1419-1422

4. Sonoda T, Hull T, Piedmonte MR, Fazio VW (2002) Outcomes of primary repair of anorectal and rectovaginal fistulas using the endorectal advancement flap. Dis Colon Rectum 45:1622-1628 
5. Van der Hagen SJ, Baeten CG, Soeters PB, Van Gemert WG (2006) Long-term outcome following mucosal advancement flap for high perianal fistulas and fistulotomy for low perianal fistulas: recurrent perianal fistulas: failure of treatment or recurrent patient disease? Int J Colorectal Dis 21:784-790

6. Van der Hagen SJ, Baeten CG, Soeters PB, Beets-Tan RG, Russel MG, Van Gemert WG (2005) Staged mucosal advancement flap for the treatment of complex anal fistulas: pretreatment with noncutting Setons and in case of recurrent multiple abscesses a diverting stoma. Colorectal Dis 7:513-518

7. Zimmerman DDE, Delemarre JBVM, Gosselink MP, Hop WCJ, Briel JW, Schouten WR (2003) Smoking affects the outcome of transanal mucosal advancement flap repair of transsphincteric fistulas. Br J Surg 90:351-354

8. Mizrahi N, Wexner SD, Zmora O et al (2002) Endorectal advancement flap: are there predictors of failure? Dis Colon Rectum 45:1616-1621

9. Lunniss PJ, Sheffield JP, Talbot IC, Thomson JP, Phillips RK (1995) Persistence of idiopathic anal fistula may be related to epithelialization. Br J Surg 82:32-33

10. Buchanan GN, Sibbons P, Osborn M et al (2005) Experimental model of fistula-in-ano. Dis Colon Rectum 48:353-358

11. Jun SH, Choi GS (1999) Anocutaneous advancement flap closure of high anal fistulas. Br J Surg 86:490-492

12. Williams JG, Farrands PA, Williams AB et al (2007) The treatment of anal fistula: ACPGBI position statement. Colorectal Dis 9:18-50

13. Safar B, Jobanputra S, Sands D, Weiss EG, Nogueras JJ, Wexner SD (2009) Anal fistula plug: initial experience and outcomes. Dis Colon Rectum 52:248-252
14. Van Koperen PJ, Ten Kate FJW, Bemelman WA, Slors JFM (2010) Histological identification of epithelium in perianal fistulae: a prospective study. Colorectal Dis 12:891-895

15. Mitalas LE, Schouten SB, Gosselink MP, Oom DM, Zimmerman DD, Schouten WR (2009) Does rectal blood flow affect the outcome of transanal advancement repair? Dis Colon Rectum 52:1395-1399

16. Mitalas LE, van Wijk JJ, Gosselink MP, Doornebosch P, Zimmerman DD, Schouten WR (2010) Seton drainage prior to transanal advancement flap repair: useful or not? Int J Colorectal Dis 25:1499-1502

17. Rojanasakul A (2010) Comments to the invited comment "LIFT procedure: a simplified technique for fistula in ano". Tech Coloproctol 14:53-54

18. Sileri P, Franceschilli L, Angelucci GP et al (2011) Ligation of the intersphincteric fistula tract (LIFT) to treat anal fistula: early results from a prospective observational study. Tech Coloproctol $15: 413-416$

19. Kiehne K, Fincke A, Brunke G, Lange T, Fölsch UR, Herzig KH (2007) Antimicrobial peptides in chronic anal fistula epithelium. Scand J Gastroenterol 42:1063-1069

20. Bataille F, Rohrmeier C, Bates R et al (2008) Evidence for a role of epithelial mesenchymal transition during pathogenesis of fistulae in Crohn's disease. Inflamm Bowel Dis 14:1514-1527

21. Mitalas LE, Gosselink MP, Zimmerman DDE, Schouten WR (2007) Repeat transanal advancement flap repair: impact on the overall healing rate of high transsphincteric fistulas and on fecal continence. Dis Colon Rectum 50:1508-1511 